\title{
MUSLIM SCHOOLGIRLS' IDENTITY AND PARTICIPATION IN SCHOOL-BASED PHYSICAL EDUCATION IN ENGLAND
}

\author{
Jane E. McGee ${ }^{1}$ and Ken Hardman ${ }^{1}$ \\ ${ }^{1}$ Institute of Sport \& Exercise Science, University of Worcester, United Kingdom
}

\section{SUMMARY}

This article draws from an ethnographic case study of a group of Muslim schoolgirls at two schools in England. It examines the issues surrounding their religious and ethnic identity and whether this conflicts with participation in school-based Physical Education (PE). Social Identity Theory underpinned the study, focusing the research and interpretation of empirical data gathered over a period of twenty months, mainly by in-depth semi-structured interviews to explicate the PE experiences through employment of a qualitative methodology.

The social categories of ethnicity and religion play a key part in shaping the identity of Muslim schoolgirls. The girls perceive PE as a subject, which allows for freedoms not found elsewhere in the curriculum and they recognise the importance of physical activity. The study confirms the findings of previous research, which found that issues of kit, fasting during Ramadan and extra-curricular activities posed problems for Muslim pupils; these are features, which are especially compounded when teachers are not aware of the issues.

The findings demonstrated the exclusionary nature of traditional physical education settings. The experiences of pupils were more reliant upon the quality of individual teachers. Multi-cultural and racism-awareness courses appear to be indispensable for a better understanding of the pupils, and making them available to all teachers, regardless of their hierarchical standing, can be advantageous.

Key Words: identity, Islam, muslim schoolgirls, physical education, religion.

\section{INTRODUCTION}

The norms and values of religion and culture are powerful forces in the lives of individuals, families and communities all over the world. Pervasive in the lived experience of being a Muslim is Islamic culture: "[...] The code of living is expressed through Islamic laws laid down in the Shari'ah. These codes imbue Islamic culture, giving meaning to the way in which Muslims make sense of their lives, behave, dress, eat and drink" (Benn, 1996, p. 6). According to Abbas (2004), in "Britain, the burgeoning interest in religion has come from both an awareness within the ethnic minority population of Islam and from its heightened international profile" (p. 27). Over the years, descendents of many of the first generation immigrants of Asian origin have gradually assimilated into British society by adapting to various British customs and traditions; nevertheless, they may wish to preserve specific characteristics of their cultural heritage. Such retention is indicative of "pluralism" (Anwar, 1985; Verma \& Bagley, 1979). However, the "present is also a period in which subsequent generations of British South Asian Muslims have begun to question their parents' religious and cultural values" (Abbas, 2004, p. 28). This questioning can extend to the potential conflict that Muslim students have between their religious identity and participation in school-based Physical Education (PE). The major defining aspect of the study from which this article is drawn was identifying ways in which Muslim schoolgirls of $\mathrm{Pa}$ kistani origin, perceived and negotiated their distinctive identities as Muslims, more specifically how religion, culture and gender might influence their participation in $\mathrm{PE}$, a curriculum subject that has traditionally struggled to maintain standardisation in dress and involvement.

There are some 1.6 million Muslims living in Britain, comprising three per cent of the total popu- 
lation and over half $(52 \%)$ of the non-Christian religious population. Islam and Muslims are thus part of the mosaic that comprises modern Britain, with half of the Muslim population being British born. There are over 400.000 Muslim pupils in school education. The faith commitments of Muslim pupils and their families encompass all aspects of everyday life and conduct, including daily life in school. It is important, therefore, that educators understand how they can respond positively to meeting the needs of Muslim pupils.

\section{The identity of Muslims schoolgirls}

At the heart of the study was the notion of identity, "a highly complex concept, which is difficult to elucidate" (Jacobson, 1998, p. 152) but Tajfel's (1978) conceptualisation of "social identity" provides a useful dynamic starting point for the analysis of ethnic, religious and national identities. The notion of social identity as dynamic was central to this study both because at a collective level, there appears to be inter-generational changes taking place in perceptions of nationality and ethnicity and religion within the $\mathrm{Pa}$ kistani community, and also at the individual level, participants have "identity options" (Rex \& Josephides, 1987) when referring to the situation of second generation British Asians. Certainly, because of their status as adolescent females and of their particular circumstances, as the children of immigrants, they may be more likely to feel that identity is an ambiguous and slippery concept. Social identity theory also addresses the issue of potential problems resulting from participation in two cultures. Tajfel (1978) discussed the likelihood that identification with two different groups can be problematic for identity formation in ethnic group members because of the conflicts in attitudes and values (including cultural and religious) and behaviours between their own and the majority group. Where helpful, other theoretical perspectives were called upon to increase understanding of emergent issues for example the notion of "embodiment" and "physical capita" in relation to the significance of symbolic dress forms some of the Muslim females adopted (Bourdieu, 1993, p. 21 ). The construction of profiles of British Muslim identity is a complex task with data suggesting a new process model of ethnic and national identity, which incorporates rootedness, differentiation, confusion and transcendence (Hutnik \& Street, 2010).

\section{The impact of Muslim female identity upon participation in school-based PE}

Previous studies (Benn, 2005; Carroll \& Hollinshead, 1993; Dagkas \& Benn, 2006; Williams \& Bedward, 2001) of participants' experiences in PE have demonstrated that it is a subject, which has the po- tential to give rise to a number of varied and contextualised reactions. As such, it is necessary to further question the perceived character of a subject that seemingly provides the foreground for a number of educational experiences, which could be considered as unique in comparison with the majority of other subjects. The specificities of $\mathrm{PE}$, in regards to its place within curricula in comparison with other subjects, are worthy of interrogation in relation to the affects upon the children and young people. These varied affects are considered as being dependent upon the situational characteristics of the learner in context. Further, such research is consequently relevant to the understanding of how Muslim females experience the various elements of PE.

It is important to consider whether the experiences of Muslim females differ significantly from gender inequalities, which have been found to exist within school-based PE (Hargreaves, 1994; Lenskyj, 1990; Scraton 1992; Talbot, 1993). In promoting inclusion, the English National Curriculum reinforced the perception that PE is integral to the development of social skills that enable pupils to become members of their cultural community (Skidmore, 2004). The literature indicates that $\mathrm{PE}$ is rooted in the traditions of motor elitism and participation (Goodwin, 2007; Scraton 1992; Talbot, 1993). In England, as elsewhere, PE teachers are not renowned for their sensitivity to difference; they are a remarkably homogenous group (mostly white, young and non-disabled) and with a history of successful involvement in sports-related activity themselves, they often show little empathy with others less talented or motivated in their subject area, and are often resistant to equity issues (Armour \& Jones, 1998).

For the Muslim female, sporting participation in school may conflict with the Islamic requirement for modesty. Carroll and Hollinshead (1993) reported that the wearing of the sports uniform caused embarrassment for both male and female students and feelings of guilt and shame were exacerbated when many of the activities were held in public places such as playgrounds and community parks. Communal showers caused severe problems even to the extent that some students absented themselves from school.

In considering how participation in PE and School Sport is influenced by Islam, it should be stated that there is no general prohibition from participation in sport for females in Islam (Lindsay, McEwan, \& Knight, 1987). According to Benn (1996), Islam and $\mathrm{PE}$ share some common concerns, the central issue being control of the body, in time and space, in rituals, in cleanliness, in dress, in the control of diet and 
pursuit of a healthy body. Islamic scholars emphasize that health and fitness are equally important for both sexes and should be maintained by regular physical activity. The Muslim Council of Britain Guidance (2007) "Meeting the Needs of Muslim pupils in state schools" recognises the high importance of education in Islam and the need for all to pursue knowledge and learning. Within the document, there is much support for children's participation in a broad and balanced PE programme with regard for Islamic requirements.

"Physical education is a very important part of school life and full participation is to be encouraged, in order to develop a healthier lifestyle [...] There are some basic Islamic requirements for modesty which need to be considered in order to remove any unnecessary barriers for Muslim pupils to participate fully in physical education and swimming in particular" (Muslim Council of Britain, 2007, p. 36 ).

In England, all children of school age have entitlement to PE within the National Curriculum. Directions of agencies such as the Muslim Education Trust recommend that Muslim children do participate, provided that Islamic requirements are met: dress, (track suits are considered acceptable,) changing and showers, (privacy is paramount and communal nudity forbidden), single sex provision after puberty, and avoidance of contact activities between sexes. The dress issue is particularly problematic for Muslim pupils in swimming. Where Islamic requirements are not met, the recommendation is that Muslim children should be exempt from PE (Sarwar, 1994). This creates a dilemma between Islamic and State education requirements. Furthermore, the available secondary school research into the experiences of Muslim adolescent girls (Carroll \& Hollinshead, 1993; Clyne, 1994; Dagkas \& Benn, 2006; Scraton, 1992) identified PE kit and compulsory showers as significant factors that contributed to some girls' negative perceptions and experiences of PE.

In a recent case study of schools in England in a large multi-cultural city, Benn et al. (2008) reported that problems arose when Muslim parents started withdrawing their daughters from PE lessons on religious grounds. Rhetorically, the social, political and education context is one of inclusivity and embracing of cultural diversity. For all children, there is a statutory national curriculum that includes PE, and a commitment to religious freedom and upholding of the human right to "manifest one's own religion". It is also important to note that Islamophobia and concerns about the hijab are regularly evidenced in the UK (and European) experiences of Muslim people and in media discourse (Fekete, 2008; Richardson, 2004; Runnymede Trust, 1997).

From the so-called BASS Project (Benn et al., 2008), in relation to PE, the religiosity of some Muslim families led to preferences to embody faith in ways that were denied in the traditional systems and structures of the PE/School Sport participation environment in England. Such embodiment refers to body modesty, covering arms, legs and head, and gender segregation, considered essential to belief and to identity as Muslim women. Traditional cultural expectations in PE/School Sport systems such as mixed-sex lessons and shorts/tee-shirts were barriers to participation for these families, hence withdrawal. The problem was not with participating in physical activity but with systems and structures that denied preferences to embody faith. Good practice features were identified from some schools and shared in final guidance. Common to these were principles of flexibility, respect for personal choice, and accommodation of difference, for example, including the young people in kit design. The emphasis was on making changes to be more inclusive. The most important point was giving access to participation. In the schools, least difficulties arose where parents were fully informed of expectations and strong links had been developed, often through community women-only sporting events. The Project's findings centred on increasing understanding of the issue itself and criticizing the structural barriers to participation. Most importantly, the English context of the inclusion/ exclusion debate surrounding adherence to religious requirements in $\mathrm{PE}$ in the state education system was essential to understanding how to resolve inter-cultural tensions. Such a problem concerning requests to allow respect that arose in one English city would not have arisen in some countries, for example, where outward manifestation of belief is denied or in others where it is compulsory.

In relation to gender and PE/School Sport, one area, worthy of investigation is the significance of control over the body. Women in Islam are controlled or control themselves in terms of religious requirements through bodily discipline concerning where, when and how the body must appear in public to »embody« Islamic principles. Similarly, "sports as embodied practices are one of the arenas within which the social struggle for control over the physical body occurs" (MacClancy, 1996, p. 15). The struggle for Muslims in the arena of PE and sport then is related to conflicting tensions for control over acceptable ways of using the body. In England, due to issues of modesty, the traditional PE kit continues to 
be seen as problematic by many girls and young women (Benn, 1998; Kamiyole, 1993).

\section{METHOD}

The study, which involved a qualitative analytical approach, endeavoured to represent two groups of Year 11 (age 15-16 years) Muslim girls as a single case. This methodology is congruent with the fundamental epistemological and methodological characteristic that social organisations are constructed on purposeful actions of individuals as they negotiate their social roles and define status within a group. The research embraced an interpretive exploration that provided awareness and understanding of the Muslim female identity impacts upon participation in school-based PE. The emphasis in the study was on providing an understanding of the views and experiences that participants attach to the complexities that are involved in their participation in PE.

\section{Data Collection}

\section{Semi-structured interviews}

For consistency with methodological issues, interviewing was considered to be the most suitable method of data collection. Data were gathered by means of in-depth interviewing, using semi-structured interview schedules. The questions initially formulated for the two interview schedules with the Muslim schoolgirls were based on the literature review and pertinent aims of the study. A number of issues were investigated including identity and school ethos. The in-depth interview is a powerful way to elicit research data. To maximise results, the researcher has to "actively listen", to keep the interview "focused", "infilling and explicating" where data is lacking and identifying clues from respondents. Furthermore, when interviewing pupils, the researcher had to demonstrate that she had the necessary qualities to engage with respondents, and yet still remain detached. Each experience was achieved through the management of impressions (Goffman, 1990), as well as through the utilisation of appropriate social science methods. It was important to conduct a pilot study prior to the main research to establish appropriate questions for the semi-structured interviews and also for the systematic observation sheets. Black's (1999) advice to avoid over-complicated questions was also useful when reviewing feedback and in ensuring that participants understood the questions. Asking about abstract concepts such as identity and school ethos was avoided as were leading questions. Where appropriate, the wording was simplified as the pilot study progressed. Due consi- deration was also given to politically correct language. With criticism (Marshall \& Rossman, 1989) of interviewing as the sole method of data collection in mind, whilst it was the principal research method of data collection in the study, additional information was obtained through attendance registers and systematic observations of PE lessons.

\section{Systematic Observation}

In order to investigate whether Muslim female identity impacts upon participation in school-based PE, systematic classroom observation was carried out. The observation was intended to show if Muslim schoolgirls had different levels of engagement with their work and different types of interaction with their teachers than non-Muslim pupils.

\section{Ethical considerations}

Entry to the PE setting was negotiated first with the Head of Department and then with the individual staff to whom the research was outlined, both verbally and in writing. As the research also involved direct contact with individual children, parental and child permission was acquired. Pseudonyms were used for the schools and the pupils to ensure confidentiality.

\section{Sampling}

The groups of pupils selected were not intended to represent some part of the larger world but to offer instead an opportunity to glimpse the complicated character, organisation and logic of culture. The study was confined to a sample of ten Muslim girls in two schools in year 11; the sample actually consisted of all of the Muslim female pupils in that year group.

\section{Geo-demographic settings of the schools}

The Borough of Dudley was chosen as the area for the research. Dudley, part of the West Midlands conurbation is located south of Wolverhampton and is the largest town in the "Black" country. The city of Birmingham is located approximately 10 miles away.

\section{School 1 - Birchincliffe School (psendonym)}

This is a slightly larger than average 11-16 comprehensive school with 1.177 pupils on the school roll. The school is non-denominational. Approximately $8 \%$ of pupils are of Muslim faith

\section{School 2 - Chamberlain School (pseudonym)}

For means of comparison, a second school, also in Dudley MBC, was selected. The school has 1.366 
pupils in the age range 11-16, the majority of whom are from socially deprived areas. The total number of Muslim pupils in the school is 20 .

\section{Data Analysis}

The analysis involved identification of patterns or themes arising in the data. Such identification influenced the direction of research, for example, facilitating the structuring of subsequent interviews, ordering and re-ordering of data. This involved identifying salient, grounded categories of meaning held by the participants in their particular setting (Marshall \& Rossman, 2006) with a focus on discovering patterns, themes and categories in data that were not pre-determined by experimental hypotheses prior to data collection.

Preliminary analysis of information generated by the girls revealed a number of linked themes, which facilitated the formulation of broad categories. Further analysis established a consolidated set of categories, variously embracing: the shaping of identity; the importance of religion; relationships with parents and friends; tensions between religious identity; and school-based PE including dress code/kit issues, changing facilities and teacher understanding of Ramadan.

\section{Findings}

There were a number of noteworthy issues which were discussed in the interviews and, consequently, a number of core themes emerged, the first of which related to the identity of Muslim schoolgirls. As indicated in the earlier paragraph on ethical considerations, in the ensuing text, pseudonyms for the study's participants and their schools are provided applied to protect identity and ensure confidentiality.

\section{Identity}

The distinctive attribute of the Muslim females interviewed was not necessarily their physical appearance, although this was a significant part, but also cultural values: a collective pool of values, customs and behaviour (Verma \& Ashworh, 1986) with inter-connectedness of faith, body and identity (Benn, 2009). Soraya and Laila were both indigenous, second-generation British and both described themselves as British Pakistani. Laila spoke of the English culture being also her culture and this view was shared by the majority of the girls interviewed, with the exceptions of identical twins Pardaj and Rabiya who described their ethnic identity as Pakistani Muslim without any reference to a British component. The girls defined their identity by looking at Asian and British components and adopting and adapting aspects from both cultures to construct their identity. Pardaj, Rabiya and Lafiza embodied their faith more than did the other girls in the sample. Munira (Chamberlain School), a close friend of Lafiza, chose not to wear the headscarf with her parents' approval:

Like she wears a scarf (pointing to Lafiza) and I don't; my Dad goes to me like it's your choice and my Mum, like if you don't wonna wear it you don't 'ave to. Well if you go to the Mosque then obviously you have to wear it.

The Islamic feature of modesty and the importance of religion were important to all of the girls in the sample as exemplified in the following quotations:

A girl who wears a short skirt and showing too much of herself has no self respect. The school should do more to stop them, like say skirts have to be a certain length but they don't do anything (Madhia, Birchincliffe School).

Well, yes it's my whole life! It's fasting during Ramadan, praying and reading the Qur'an. My parents sometimes have to remind me to pray but I don't mind 'cos I think it's important (Laila, Birchincliffe School).

According to Basit, (1995) "it is very rare for a Muslim to become a non-believer or even non-practising" (p. 281). This was confirmed in the interviews. Soraya and Laila both stressed the importance of their religion. For Laila, Islam was not just a religion but a way of life: The girls spoke of religion as a guide that tells them what to do as giving life meaning and something to live by. The girls maintained that parental pressure to pray was moderate but they did not mind being reminded to pray due to the importance of religion. The literature also describes relationships with parents and friends as an important factor in the shaping of identity. Relationships with parents were described as constructive. Safath expressed pleasure in having a harmonious relationship with her parents; she did not consider her parents as over-protective but rather she justified this as her parents being concerned for her safety and welfare. She also believed that her parents understood the situation:

I am so happy that I get along with my parents so well I suppose it is about bonding when you are small, I mean I was really close to my Mum and my Dad and I bonded with them so well and they are both understanding parents and some parents are not like that (Safath, Birchincliffe School).

Laila also expressed a similar outlook in that her parents were concerned about her choice of clothes 
and she joked that they thought that she was into "Devil worship" due to the predominance of red and black clothing in her wardrobe. The majority of girls in the sample had friends who were Muslim. Rabiya (Chamberlain School) reported the ethnic solidarity of being able to feel more at ease with other Muslims because:

[...] you can talk in our own language and just have fun you can't do that with English people, white people.

Pardaj stated that they did not "hang out" with white girls because they would prefer to spend time with friends who shared their way of life. On the other hand, Hafsa stated that she had both Muslim and non-Muslim friends with whom she would socialise in and out of school. Pardaj and Rabiya expressed a strong ethnocentric bias towards their own culture but, nevertheless, they did like the "hip hop" music and the fashion. Both Laila and Soraya had non-Muslim friends and explained that this was not problematic. Laila suggested that her friends did attempt to understand her religion and culture:

Friends understand, or try to understand our religion and culture like they don't eat in front of me when I'm fasting and try and force me into bars [...] Getting drunk and not being able to remember is not my idea of a good night out (Laila, Birchincliffe School)

Although Laila expressed positive sentiments to fashion, music and dance, she did not like the permissiveness in Britain such as drunkenness. She stated:

Yeah, like it's not my idea of having a good time if you can't remember what you did 'cos you got drunk. Most think it's cool to drink as much as you can but what's cool about that? I can't see the point.

\section{Impact of Muslim female identity upon participation in school-based PE}

The majority of the girls interviewed reported that they enjoyed PE. The notion of it being a subject where they had a »time out « from other lessons is shown in comments where girls did not think of PE in the same light as their other lessons. It meant something different to them. Munira (Chamberlain School) described how PE was a subject, which she observed as being a time and place when such enjoyment was a plausible outcome.

I actually like PE 'cos you can do anything you like. So I like it, it’s like spending you own time, like you can do sports wherever you want to. You can be sporty, there's no writing and there's no exams instead of doing writing. It's like a "doss" in some ways.

Similar opinions were expressed by Pardaj and Rabina, who both stated that they liked PE as it was a welcome break from subjects such as English where there "was too much writing". The enjoyment of lessons was further confirmed by lesson observations. The girls varied in ability and this did have some relationship to their enjoyment of lessons. The enjoyment of PE was also, dependent on the activity in question. Few girls expressed positive attitudes to weightlifting as opposed to netball or badminton. Soraya, who was a keen performer in PE and an excellent role model to her peers, reported positive attitudes to PE, but she drew the line at weightlifting!

In all cases there were a number of key factors that caused tensions for the girls' religious identity. These related to kit, changing facilities, Ramadan and teacher understanding.

\section{Kit Issues}

The Islamic concern for modesty was also an issue, which permeated the interview responses at both sample schools. The PE dress code is an important dimension because of this Islamic requirement. Both schools had adopted a kit policy where Muslim students could wear track suit bottoms in the summer and winter. The girls appreciated this as they did not want to show their legs anyway. They felt more conscious in the summer months when their non-Muslim counterparts had to wear shorts. Madhia and Safath from Birchincliffe School stated that the school should introduce a standard track suit bottoms as part of the PE kit. However, the kit policy at Chamberlain school was about to change as the new Head of PE was due to implement a new shorts for all policy purely for aesthetic reasons.

\section{Changing facilities}

Privacy is paramount to Muslim pupils. The changing facilities at Birchincliffe and Chamberlain School were both open plan and all of the girls in the study reported changing in the toilets either on a regular basis, or for every session. Munira and Laila were the only girls who stated that they frequently changed in the communal area. Hafsa described her friend Iffat who did not participate in PE due to issues of modesty.

Iffat doesn't like doin' PE 'cos she wears that Scarf on her head and every Friday she (doesn't), like come to school. 
Showering was not a salient issue as showers were no longer compulsory due to timetable constraints.

\section{Ramadan}

Religion is important in the lives of the girls in the sample and is not just confined to belief. The comments of the girls in this research show that they always fast during Ramadan. It was necessary to explore if they found it difficult to practise their religion as well as participate in PE.

At Birchincliffe School, the girls were expected to participate in some way in PE and this was exacerbated by "Athletics" occurring during Ramadan at the time the research was carried out. At Chamberlain School the girls' comments indicated that they did not participate in PE during Ramadan.

When it's Ramadan, we don't participate in PE.

We can just sit there and watch everyone or we can just do some coursework, go into another class and do something (Lafiza, Chamberlain School).

We can just sit there and watch everyone or we can just do some coursework, go into another class and do something (Hafsa, Chamberlain School).

Also there was an onus on the students to approach the teacher during Ramadan to excuse themselves from the activity:

They let us sit out (Rabiya, Chamberlain School) [...] but you have to ask (Pardaj, Chamberlain School);

They know that's it's Ramadan, but we tell 'em, before we do PE like (Hafsa, Chamberlain School).

The responses to pupils from both Birchincliffe and Chamberlain Schools indicated that teachers varied in their approach to Ramadan. This is exemplified in Safath's comment:

I like the way Miss Blanchard is when you are fasting; she will be understanding, whereas some will shout "why ain't you doing it?"; she will come up to us privately and ask if we are OK and will help give us things to do, which are OK whereas other teachers they say you've got to do it; they don't understand that we can get thirsty and we can't drink so times it is a bit hot and it is a bit hard to do PE when they are being sarcastic to us.

Pardaj (Chamberlain School) also stated that teachers varied in their approach to Ramadan:
Some teachers they are strict and others are alright about it, it varies you know.

Madhia (Birchincliffe School), in contrast, believed that teachers did understand but added another dimension:

I think they do understand why we fast, er [...] but I think they just don't care personally I don't think it is a consideration.

As the research progressed the girls did make some suggestions of how they believed the teachers could adopt a more uniform approach to Ramadan.

Well it's all about them learning if they want to. They do know I know most of the teachers know and quite a lot of pupils will know they just don't take it into consideration that's it (Madhia, Birchincliffe School).

I think we should be able to miss PE when Ramadan is on because I feel tired. It is only for one month and we should be given the choice to sit out. We can sit out for one lesson but we should be able to sit out when we are fasting 'cos I just get really tired. I mean Ramadan lasts for one month so it would mean er six lessons. We should be given the choice to sit out, I am not making an excuse. It is only for six lessons (Abia, Birchincliffe School).

Some of the girls were also conscious of other pupils' reactions to their lack of participation during Ramadan and believed that the teachers could do more to raise their own levels of awareness and those of other pupils. The incidence of victimisation by teachers and other pupils was not universally shared but it did cause concern to some of the pupils as did the perceived lack of concern by the teachers.

Safath (Birchincliffe School) reported an incident, which had occurred during Ramadan:

Yes we get comments like you don't need to sit in the sun you are already tanned and do we all eat chipates? The boys say the things to your face the girls say it behind your back. One of the popular boys asked me about the chipates and although the teacher warned him it still happened again

Madhia's (Birchincliffe School) comment indicated her frustration at the incidents of victimisation coupled with a laissez-faire approach from the teachers:

We talk to the teachers ourselves but sometimes the teachers they don't really care, like they don't do really nothing about it and so I just think I might as well leave it 'cos there's no 
point wasting your time 'cos they don't really do nothing about it. If it's still going to carry on then we might as well put up with it. Nothing much happened, you can report it but it don't really change anything.

Lafiza stated that the non-Muslim girls resented their lack of participation because some of their non-Muslim counterparts also wanted to opt out of PE but for non-religious reasons.

Some of the other girls they don't like it because they don't want to do PE either (Lafiza, Chamberlain School).

They say it's not fair and then they will stare or talk about us behind our backs (Pardaj, Chamberlain School).

\section{DISCUSSION}

Muslim girls have been stereotypically represented as passive victims of oppressive, patriarchal home cultures (Ramji, 2003). The discourse of cultural pathology positions Asian Muslim femininities as inherently troubled and problematic (Shain, 2002). The evidence from views of Muslim girls' own accounts of their identities and lives demonstrates far from being passive cultural "victims". Muslim schoolgirls in the present study emphasised that they had happy home lives in which they enjoyed parental support for a wide range of personal, social and educational choices. This supports research by Archer (2002; 2005) and Basit (1997). The girls also adopted distinctly hybrid, British/English Muslim identities, arguing that they defined themselves both by their nationality/ country of birth (English/British) and their religious identity the girls felt that these two identities were inextricably linked British. The majority of girls in the present study's sample was either born, or had come to live, in their infancy in the West Midlands Region of England meaning that the girls, who were in year 11 at Secondary School, had received all their schooling in Britain. Most of the girls in the sample perceived themselves as both British and Asian, epitomized, for example, in Lafiza's reference to her British status:

We were born in this country and we were raised here and so we see ourselves as British (Lafiza, Chamberlain School).

These findings challenge the popular assumption that Muslim girls suffer from what is called "culture conflict" as a result of being caught "between two worlds". Ramji (2003), for example, argues against the popular notion that Asian women are oppressed and damaged due to having to negotiate between two opposing worlds of home and school and she criticizes the idea that Asian women lack choice and freedom in their lives. Nevertheless, ethnic minorities make their own decisions about which features of their culture of origin they want to retain and which ones they want to abandon. Similarly they embrace specific characteristics of the majority culture of their adopted country and reject others. The latter include the dress code in school and leisure activities such as the culture of drinking alcohol and its subsequent effect on behaviour, which is seen in a negative light. Thus, they create their own cultural identity by means of a process of analysis and synthesis, which is not always based on rational judgement. While many cultural traits are adopted or abandoned because of their relative usefulness or obsolescence, others are preserved merely because the minority groups like these customs and perceive them as an essential part of their cultural identity. Most girls in the study's sample admitted that they liked almost everything pertaining to the Asian way of life. The likeable features mentioned by some were: adherence to Islam; dress code; arranged marriage; and the way weddings and festivals were celebrated. The respect and closeness within the family were seen by almost all the girls as a positive aspect of Asian culture.

The girls do not choose an identity independently of their parents. They know the boundaries and respect the limits imposed by the parents. Issues, which emerged from the girls' responses, related to the relationship structures with parents together with secondary issues concerning dress codes. There were no signs of stress apparent during the interviews or responses leaving an impression of identity being shaped consentfully. Hafsa illustrated that although there were "rules", she did not consider them as unreasonable.

Peers are an important feature of a child's school experience (Lomax, 1978). It is clear that an important factor influencing the friendship patterns of the Muslim girls in the sample is the similitude of circumstances, mores and values. Newcomb (1961) found that the most stable friendships developed formed between those who shared similar backgrounds. Similar others will serve to validate their beliefs and increase the possibility of engaging in similar activities (Rubin, 1973). The Muslim girls have been socialized to live their lives in a particular way. They, therefore, refrain from indulging in similar pastimes as their non-Muslim peers and their contact with them is confined to the safe environment of the school.

Religion plays an important part in most British Asian communities and guides the principles around 
which they live. Sharpe (1976) argues that their religious beliefs and principles determine their moral ethics and form the social milieu in which they live into one centred around many stern requisites of behaviour. Such requisites include moral conformity, loyalty and cooperation, self-discipline, recognition of the dominant authority of the elders, respect for marriage and the advocation of modesty and restraint. However, these principles are confronted by the ethos of a capitalist and largely secular British society that impinges on the beliefs of these religious minorities, thus exerting pressure on them to adapt to the majority view.

Still, there may well be an enormous gap between religious beliefs, religious behaviour and religious prejudices (Delamont, 1980). People may believe in the teachings of a certain religion, though not practise it fully in their everyday lives. This is particularly true of British Muslims, the majority of whom originate from South Asia. However, there is a unique concept of religion embedded in Islam, which makes it a way of life. Consequently, etiquette and belief are closely connected and Muslims are required by their religion to live their life according to its teachings.

The majority of girls featured in this study showed a certain pride in being Muslim and referred to themselves as Muslims.

I'm Muslim and I'm proud to be what I am. I like the way we follow it in our family (Laila, Birchincliffe School).

When asked why religion was important, Hafsa (Chamberlain School) gave the succinct answer:

\section{It's cos we're Muslims.}

Furthermore, when the girls were asked what they thought of religion, the vast majority of them saw it as a guide and a set of rules to live by, thus equating it with morality: Madhia perceived religion as something which gave her identity and a sense of belonging. However, the religiosity of the girls was not just confined to belief. As far as religious practice was concerned, most of them prayed and read the Qur'an occasionally, but fasted regularly, since the entire family fasted during the month of Ramadan.

The centrality of the body in PE makes the subject distinctive in curriculum studies and consequently demands heightened need for teacher sensitivity and awareness of culturally diverse embodied values (Evans, Davies, \& Wright 2004; Kirk, MacDonald, \& O'Sullivan, 2006; Wright, Mac Donald, \& Burrows, 2004). Attention to the concept of embodiment of a physical identity acknowledges the material, physical, biological as well as the social whole of the "lived body"
(Garrett, 2004, p. 141). What has been underdeveloped in current debate is any sense of the spiritual self, for example of religious identity and the struggles of people in different faiths for the basic human right to "manifest one's religion or beliefs" (Human Rights Act, 1998). In terms of research that focuses on the body and inequality, PE "as the one subject area where embodiment is fundamental and central to success and attainment", has often been ignored or marginalised in broader debates about difference and education (Flintoff, Fitzgerald, \& Saraton, 2008, p. 74 ). Therefore, attention to embodiment, faith and PE could help to increase understanding for more inclusive practice. The concept gives meaning to the interconnectedness of faith, body and identity (Benn, 2009).

Understanding the notion of embodied faith offers insight into the core significance religion can have on life experience. It is particularly helpful in enabling those outside the faith to understand the lives of Muslim people more fully. For some Muslim people, private and internalised embodiment of faith is their choice, for others the adoption of hijab and more public manifestation of religious belief is central to their religious identity.

Where school PE or sport environments challenge the right of Muslim women to embody their faith, the result is inevitably non-participation, negotiation or coercion. Dominant western school and sport models have developed in the context of perceptions of body cultures and social interaction patterns that are not shared globally. Those who pursue freedom to maintain outward manifestation of "embodied faith", often as diaspora communities in non-Islamic countries, seek accommodation of difference as minorities in a predominantly secular society.

The study illustrated diversity in Muslim young people's preferences for degree of adherence of Islamic dress requirements in PE. Where embodied faith was strongest and religious identity most prominent in consciousness, then strict adherence to religious requirements was necessary. Where accommodation could not be found there were young people who just:

Did not take part in PE at all (Iffat, Chamber-

lain School).

For all of the girls, arm and leg coverage was essential to retaining their embodied faith while participating:

I would not feel comfortable wearing shorts

(Madhia, Birchincliffe School).

Being persuaded or forced to transgress from what she perceived as a religious obligation created tension 
for her sense of religious identity. Strength of belief integrating faith, body and dress was also seen in other pupils. There was less of an issue with the use of single-sex classes. However, all related to different interpretations of the requirement for body modesty as one pupil (Lafiza) could not take part where there were boys. Other pupils chose not to wear any outward manifestation of their faith preferring a private, internalised faith. Important messages of diversity and close connections between identity, body and physicality are raised in such data. The notion of embodied faith increases understanding and sensitivity to the interface of Islam and physical activity participation. Here different cultural values centred on the body can underpin tensions that need to be resolved in the search for more inclusive pedagogical practices.

Tensions between educational practices and religious belief are important because, for many Muslims faith is the dominant determinant of pervasive values, behaviours and social relations. Issues at the interface of religion, ethnicity, gender, and physical activity are not unique to Islam but have been omnipresent historically where body practices and religious beliefs have been incongruent (Coakley, 2007). The centrality of Islam reflects its status as a "core life value", and is an "important part of everyday life" (Espositio \& Mogahed, 2007, pp. 5, 21). While teachers had attempted to accommodate the needs of their pupils by making concessions on uniform and, in some cases, in organisation of teaching groups, there seemed to have been little involvement of pupils in this process. A belief that uniform rules were now accepted by students, following explanations from the teachers, was not confirmed by some of the students themselves, who, irrespective of their own culture, saw the school policy as unfair or racist. Their non-Muslim peers could wear track suit bottoms in the winter but not in the summer. The consequence of this was that the sample felt more visible during the summer months.

It was evident from the girls' comments that Ramadan was an area, which caused tensions for the Muslim girls partly in relation to the inconsistent approach adopted by the teachers. This was further exacerbated at Birchincliffe School where »Athletics« had been scheduled. The Muslim Council of Great has produced a policy document of good practice, which states that during Ramadan there should not be any physically exerting activities such as Athletics. Some of the girls were also conscious of other pupils' reactions to their lack of participation during Ramadan and believed that the teachers could do more to raise their own levels of awareness and those of other pupils. The incidence of victimisation by teachers and other pupils was not universally shared but it did cause concern to some of the pupils as did the perceived lack of concern by the teachers.

\section{CONCLUSIONS}

The findings of this study support research that has emphasised the active role of the individual in shaping an ethnic identity (Khan, 2002; Rumbaut, 1994). Identity is seen as a dynamic product that is achieved rather than simply given. British Muslims are willing to adapt to those aspects of the indigenous culture that do not clash with their religio/cultural ethos. Culture is dynamic, not static. Immigrants retain the likeable features of their culture of origin and abandon the ones they dislike. They also adopt what they are impressed with from the culture of their adopted country and reject what they find unimpressive.

Some girls clearly felt strongly about ways in which their religious identity was compromised in the isolating, unsympathetic school situations they had experienced. This was in relation to Ramadan and was particularly evident amongst those students who had experience of being in a previous school where Muslim students were not in the minority. These students were able to make comparisons and discuss their experiences of how PE teachers understood their needs surrounding Ramadan in relative terms. At both Birchincliffe School and Chamberlain School, there was a small proportion of Muslim students, and hence, there were no provisions for religious requirements such as a prayer room. The Every Child Matters agenda applies to all, including meeting the needs of even a small minority of Muslim pupils. However, teachers need the competence, confidence and materials to use existing flexibility within the curriculum. The research verifies the need for whole school and departmental policies on Ramadan that reflect mutual recognition, understanding and flexibility. The findings also present a challenge to official inspection Reports for both schools, which observe that both schools were inclusive. The Muslim Council of Great Britain's Advice to Schools suggests that more co-operative working will serve to create an environment where children feel welcomed and valued. However, even with the best of intentions, the gap between rhetoric and reality means that some pupils have significant barriers to overcome before they can experience full inclusion. Creating a community based on equal status relationships is a key element in successful inclusion and in PE the oppor- 
tunity to structure interactions certainly exists. What is clear is that casual interactions or the presence of a Muslim pupil in the PE setting is not enough to promote tolerance and acceptance. Indeed, the findings of the study suggest the move towards a more inclusive and democratic social situation in the PE class still remains a far-off goal.

\section{REFERENCES}

Abbas, T. (2004). After 9/11: British South Asian Muslims, Islamophobia, multiculturalism and the state. American Journal of Islamic Social Sciences, 21(3), 26-38.

Anwar, M. (1985). Pakistanis in Britain. London, GB: New Century.

Archer, L. (2002). »It's easier that you're a girl and that you're Asian: interactions of race and gender between researchers and participants«. Feminist Review, 5(4), 108-132. doi: 10.1057/ palgrave.fr. 9400043

Archer, L. (2005). Muslim adolescents in Europe, in Developing Identities among Adolescents. European Issues, 55-70.

Armour, K., \& Jones, R. (1998). Physical Education Teachers' Lives and Careers: PE, Sport and Educational Status. London, GBR: Falmer Press.

Basit, T. N. (1995). Educational, social and career aspirations of teenage Muslim girls in Britain: an ethnographic case study (Unpublished doctoral dissertation). Department of Education, University of Cambridge.

Benn, T. C. (1996). Muslim women and physical education in initial teacher training. Sport Education and Society, 1, 5-21. doi: 10.1080/ 1357332960010101

Benn, T. C. (1998). Exploring the experiences of a group of British Muslim women in initial teacher training and their early teaching careers (Unpublished doctoral dissertation). Loughborough University.

Benn, T. C. (2005). Race and physical education, sport and dance. In K. Green and K. Hardman (Eds.) Physical Education; Essential issues (pp. 197-219). London, GBR: Sage. doi: 10.4135/ 9781446215876.n12

Benn, T. C., Dagkas, S., Jawad, H., Miles, H., Whitworth, R., Rashid, N. S., ... Begum. F. (2008). Improving Participation of Muslim Girls in Physical Education and School Sport: Shared Practical Guidance from Birmingham Schools 2008, Birmingham City Council Launch of Guidelines. Birmingham, GBR: Birmingham City Council.

Benn, T. C. (2009). Muslim Women in Sport: A Researcher's Journey to understanding
Embodied faith. International Council for Sports Science and Physical Education, Bulletin, 55, 48-56.

Black, T. R. (1999). Doing Quantitative Research in the Social Sciences. London, GBR: Sage.

Bourdieu, P. (1993). The Field of Cultural Production Essays on Art and Literature. Oxford, GBR: Polity Press.

Carroll, B., \& Hollinshead, G. (1993). Ethnicity and conflict in physical education. British Educational Research Journal, 19, 59-76. doi: 10.1080/ 0141192930190105

Clyne, I. (1994). Beyond Bay 13. Aussie Sport Action, 5, 5-9.

Coakley, J. (2007). Sports in Society Issues and Controversies. London, GBR: McGraw Hill Higher Education.

Dagkas, S., \& Benn, T. C. (2006). Young Muslim women's experiences of Islam and physical education in Greece and Britain: a comparative study. Sport Education and Society, 11(1), 21-38. doi: 10.1080/13573320500255056

Delamont, S. (1980). The Sociology of Women. London, GBR: George, Allen \& Unwin.

Espositio, J. L., \& Mogahed, D. (2007). Battle for Muslim's Hearts and Minds: The road not (yet) taken. Middle East Policy, 14(1), 27-41. doi: 10.1111/j.1475-4967.2007.00281.x

Evans, J., Davies, B., \& Wright, J. (2004). Body Knowledge and Control: Studies in the Sociology of Physical Education and Health. London, GBR: Routledge.

Fekete, L. (2008). Integration, Islamophobia and civil rights in Europe. London, GBR: Institute of Race Relations.

Flintoff, A., Fitzgerald, H., \& Scraton, S. (2008). The Challenges of Intersectionality: Researching difference in Physical Education. International Studies in Sociology of Education, 18(2), 73-85. doi: 10.1080/09620210802351300

Garrett, R. (2004). Negotiating a Physical Identity: Girls, Bodies and Physical Negotiating a Physical Identity: Girls, Bodies and Physical Education. Sport, Education and Society, 9(2), 223-237. doi: 10.1080/1357332042000233958

Goffman, E. (1990). The Presentation of Self in Everyday Life. London, GBR: Penguin.

Goodwin, L. J. (2007). The Inclusion of Children with Physical Disabilities in Physical Education. Rhetoric or Reality? (Unpublished doctoral dissertation). University of Surrey.

Hargreaves, J. A. (1994). Sporting Females: Critical Issues in the History and Sociology of Women's Sport. London, GBR: Routledge. 
Human Rights Act (1998). A Guide to the Human Rights Act 1998. Available at http://www. justice.gov.uk/about/docs/act-studyguide.pdf.

Hutnik, N., \& Street, R.C. (2010). Profiles of British Muslim identity: Adolescent girls in Birmingham. Journal of Adolescence, 33(1), 33-42. doi: 10.1016/j.adolescence.2009.05.016; PMid:19683339

Jacobson, J. (1998). Islam in transition: Religion and identity among British Pakistani youth. London, GBR: Routledge.

Kamiyole, A. O. (1993). Physical Educators Albatross in African Muslim Societies. International Journal of Physical Education, 30, 28-31.

Khan, S. (2002). Aversion and desire: negotiating Muslim female identity in the diaspora. Women's Press.

Kirk, D., MacDonald, D., \& O'Sullivan, M. (2006). The handbook of physical education. London, GBR: Sage.

Lenskyj, H. (1990). Power and play: Gender and sexuality issues in sport and Physical activity. International Review for Sociology of Sport, 25, 235-243. doi: 10.1177/101269029002500305

Lindsay, K., McEwan, S., \& Knight, J. (1987). Islamic Principles and Physical Education. Unicorn, 13(2), 75-78.

Lomax, P. (1978). The Attitudes of Girls, with Varying Degrees of School Adjustment, to Different Aspects of their School Experience'. Educational Review, 30(2), 117-124. doi: 10.1080/0013191780300205

MacClancy, J. (1996). Sport, Identity and Ethnicity. Oxford, GBR: Berg.

Mashall, C., \& Rossman, G. B. (1989). Designing Qualitative Research. Newbury Park, CA: Sage.

Muslim Council of Britain (2007). Towards Greater Understanding. Meeting the needs of Muslim pupils in state schools. Information and guidance for schools. Available at http://www. mcb.org.uk.

Newcomb, T. M. (1961). The acquaintance process. New York, NY: Holt, Rinehart, \& Winston. doi: 10.1037/13156-000

Ramji, H. (2003). Engendering Diasporic Identities. In N. Puwar and P. Raghuram (Eds) South Asian Women in the Diaspora (pp. 227-242). Oxford, GBR: Berg.

Rex, J, \& Josephides, S. (1987). Asian and Greek Cypriot Associations and Identity. In: J. Rex, D.
Joly, and C. Wilpert (Eds.) Immigrant Associations in Europe (pp. 11-21). Aldershot, GBR: Gower.

Richardson, R. (2004). Islamophobia: Issues, challenges and action. Stoke-on-Trent, GBR: Trentham.

Rubin, Z. (1973). Liking and Loving. New York, NY: Holt, Rinehart, and Winston.

Rumbaut, R. G. (1994). The Crucible within: Ethnic Identity, Self-Esteem, and Segmented Assimilation among Children of Immigrants International Migration Review, 28(4), Special Issue: The New Second Generation, 748-794.

Runnymede (1997). Islamophobia - Its Features and Dangers. A TRUST Consultation Paper. London, GBR: Runnymede Trust.

Sarwar, G. (1994). British Muslims and Schools. London, GBR: Muslim Education Trust

Scraton, S. (1992). Shaping up to Womanhood: Gender and Girls' Physical Education. Milton Keynes, UK: Open University Press.

Shain, F. (2002) The Schooling and Identity of Asian Girls. Stoke-on-Trent, GB: Trentham Books.

Sharpe, E. J. (1976). The Limits of Inter-Religious Dialogue. British Journal of Religious Education, 16(1), 9-13.

Skidmore, D. (2004). Inclusion: The Dynamic of School Development. Maidenhead, GBR: Open University Press.

Tajfel, H. (1978). Differentiation between Social Groups. London, GBR: Academic Press.

Talbot, M. (1993). A Gendered Physical Education. In L. J. Goodwin (2007) The Inclusion of Children with Physical Disabilities in Physical Education. Rhetoric or Reality? (pp. 74-89) (Unpublished doctoral dissertation). University of Surrey.

Verma, G. K., \& Bagley, C. R. (1979). Race, Education and Identity. London, GBR: Macmillan.

Verma, G. K., \& Ashworth, B. (1986). Ethnicity and Educational Achievement in British Schools. London, GBR: Macmillan.

Williams, A., \& Bedward, J. (2001). Gender, Culture and the Generation Gap: Student and Teacher Perceptions of Aspects of National Curriculum Physical Education. Sport, Education and Society, 6(1), 53-66. doi: 10.1080/13573320123581; doi: 10.1080/713696037; doi: 10.1080/13573 320120033881

Wright, J., Macdonald, D., \& Burrows, L. (2004) Critical Inquiry and Problem-solving in physical education. London, GBR: Routledge. 
Received: March 2, 2012

Revision received: April 10, 2012

Accepted: April 28, 2012

Correspodence to: Ken Hardman, PhD Institute of Sport \& Exercise Science, University of Worcester, Henwick Grove, United Kingdom E-mail: ken.hardman@tiscali.co.uk Telefon: 001905855140 001457854262 Faks: 001905855132 